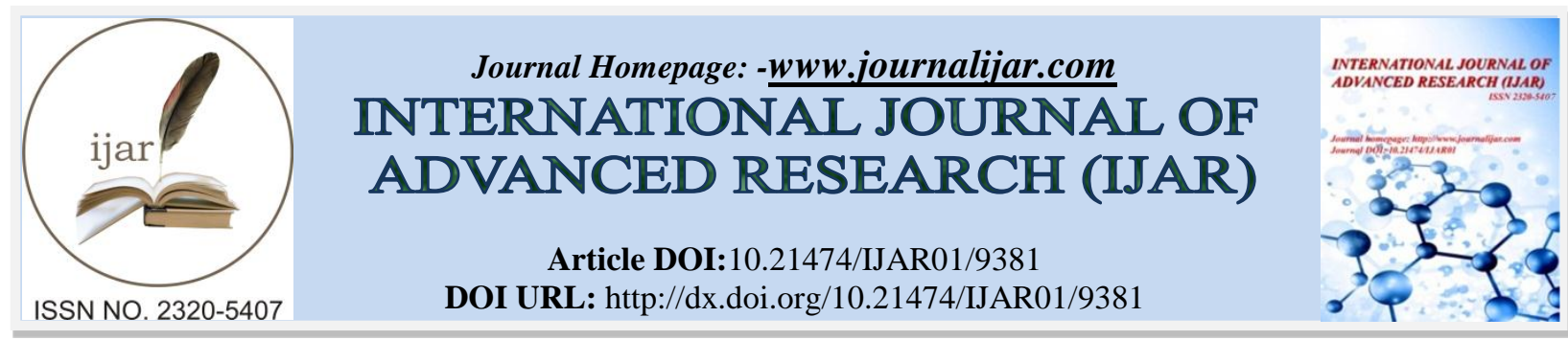

RESEARCH ARTICLE

\title{
A STUDY OF OCULAR MANIFESTATIONS IN THERMAL AND ELECTRICAL BURNS.
}

\section{Dr N.Kasturi Bai ${ }^{1}$, Dr M. Satyanarayana Reddy ${ }^{1}$, Dr K.Revathy ${ }^{2}$, Dr Manjula Bai ${ }^{3}$, Dr B.Sai Geetha ${ }^{4}$.}

1. Assistant Professor, Department of Ophthalmology, Regional Eye Hospital, Kurnool Medical College, Kurnool. AP.

2. Professor, Department of Ophthalmology, Regional Eye Hospital, Kurnool Medical College, Kurnool, AP.

3. Associate Professor, Department of Plastic Surgery, Government General Hospital, Kurnool Medical College, Kurnool,AP.

4. Post graduate, Department of Opthalmology, Regional Eye Hospital, Kurnool Medical College, Kurnool, AP.

\section{Manuscript Info}

Manuscript History

Received: 10 May 2019

Final Accepted: 12 June 2019

Published: July 2019

\section{Abstract}

A clinical Study including 100 patients with thermal and electrical burns admitted in the burns ward, Government General Hospital, Kurnool from January 2017 to December 2017 was done. A detailed ocular examination and posterior segment evaluation, wherever feasible, was done. Follow up for two months to find out sequelae and their management was done.

Copy Right, IJAR, 2019,. All rights reserved.

\section{Introduction:-}

Thermal and electrical burns involving face commonly have ocular manifestations. More than $2 / 3^{\text {rd }}$ of facial burns involve eye or periocular area and $7.5 \%-25 \%$ of all patients treated for burns have ocular involvement. Reflex blinking of eyelids in response to heat and smoke protect the cornea and eyelid margins.

Frequent ocular injuries seen as a result of facial burns include lid burns, corneal burns, foreign bodies, abrasions, perforations, contractures leading to ectropion. Chronic sequelae following thermal and electrical burns include ectropion, dry eyes, corneal opacities, cataract, and posterior segment changes leading to the low visual outcome.

The purpose of this study is to determine various ocular manifestations immediately after burns and their sequelae after two months follow up of thermal and electrical burns involving the face.

\section{Material and Methods:-}

A total of 100 patients of all age groups admitted in a burns ward, Government General Hospital, Kurnool with thermal and electrical burns involving face during the period of January 2017 to December 2017 were included in this study.

Various ocular findings were noted in all patients after detailed examination and fundus examination, OCT did in needed patients (electrical burns) who came for follow up and appropriately treated for sequelae.

Corresponding Author:-Dr M.Satyanarayana Reddy.

Address:-Assistant Professor, Department of Ophthalmology, Regional Eye Hospital, Kurnool Medical College, Kurnool. AP. 


\section{Observations:}

\section{Age Distribution:}

Of 100 patients in this study, $6 \%$ are below 10 years, $17 \%$ are $11-20 \mathrm{yrs}, 43 \%$ are $21-30 \mathrm{yrs}, 20 \%$ in $31-40 \mathrm{yrs}$, $4 \%$ are between $41-50 \mathrm{yrs}, 8 \%$ are between $51-60 \mathrm{yrs}$ and $2 \%$ are above $60 \mathrm{yrs}$.

Most common age group involved is 21-30 yrs (43\%).

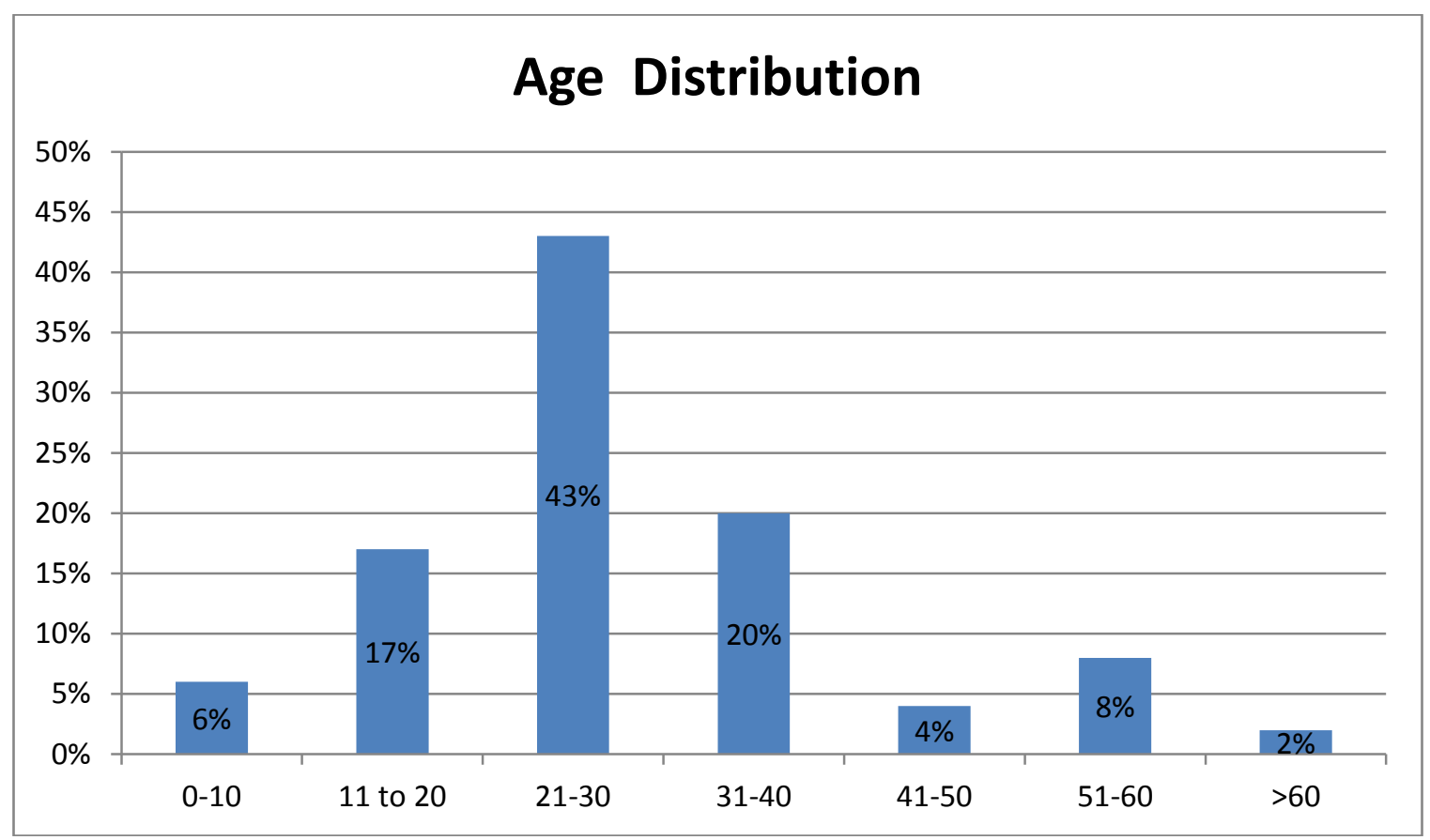

\section{Sex Distribution:}

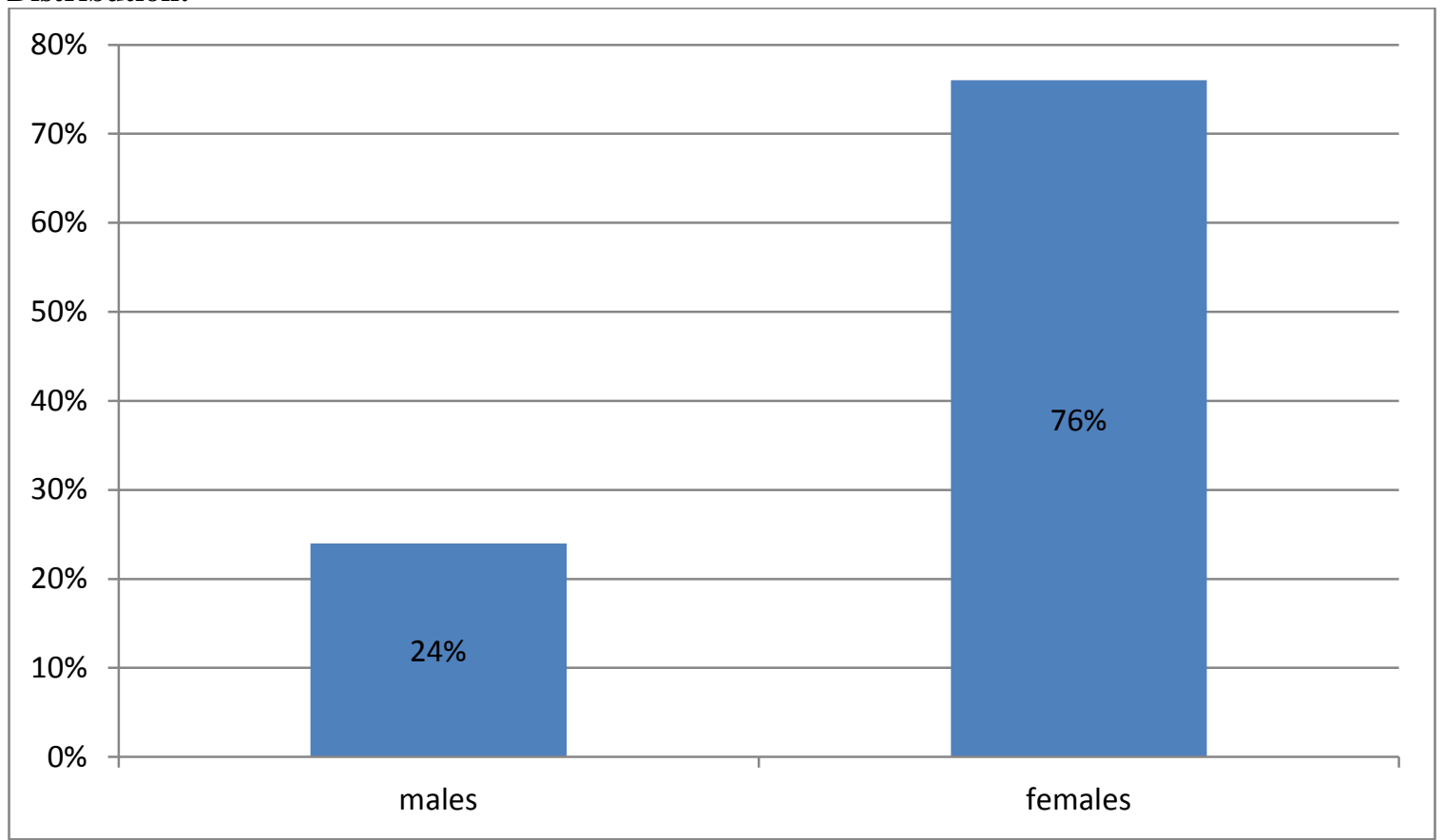

Of 100 patients, 24 patients were males, and 76 patients were females. 
Nature of injury:

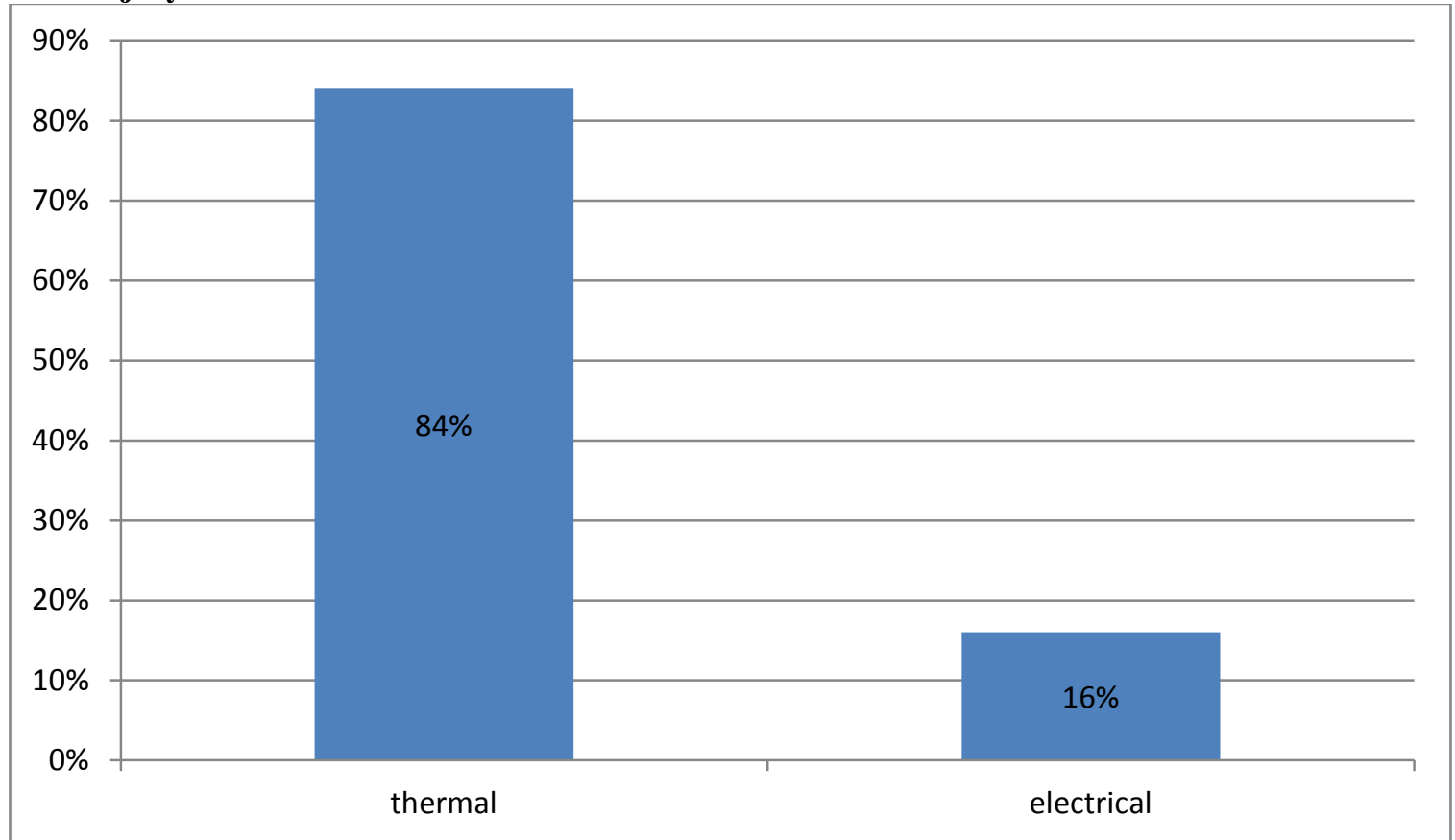

Of 100 patients, 84 patients had thermal burns, and $16 \%$ had electrical burns.

And in thermal burns, 70 patients had burns due to petroleum products like kerosene and petrol, 8 had burns due to hot oil, and 6 with fall of hot water and steam. Of $16 \%$ of electrical injuries, $14 \%$ had contact burns, and $2 \%$ had flash burns.

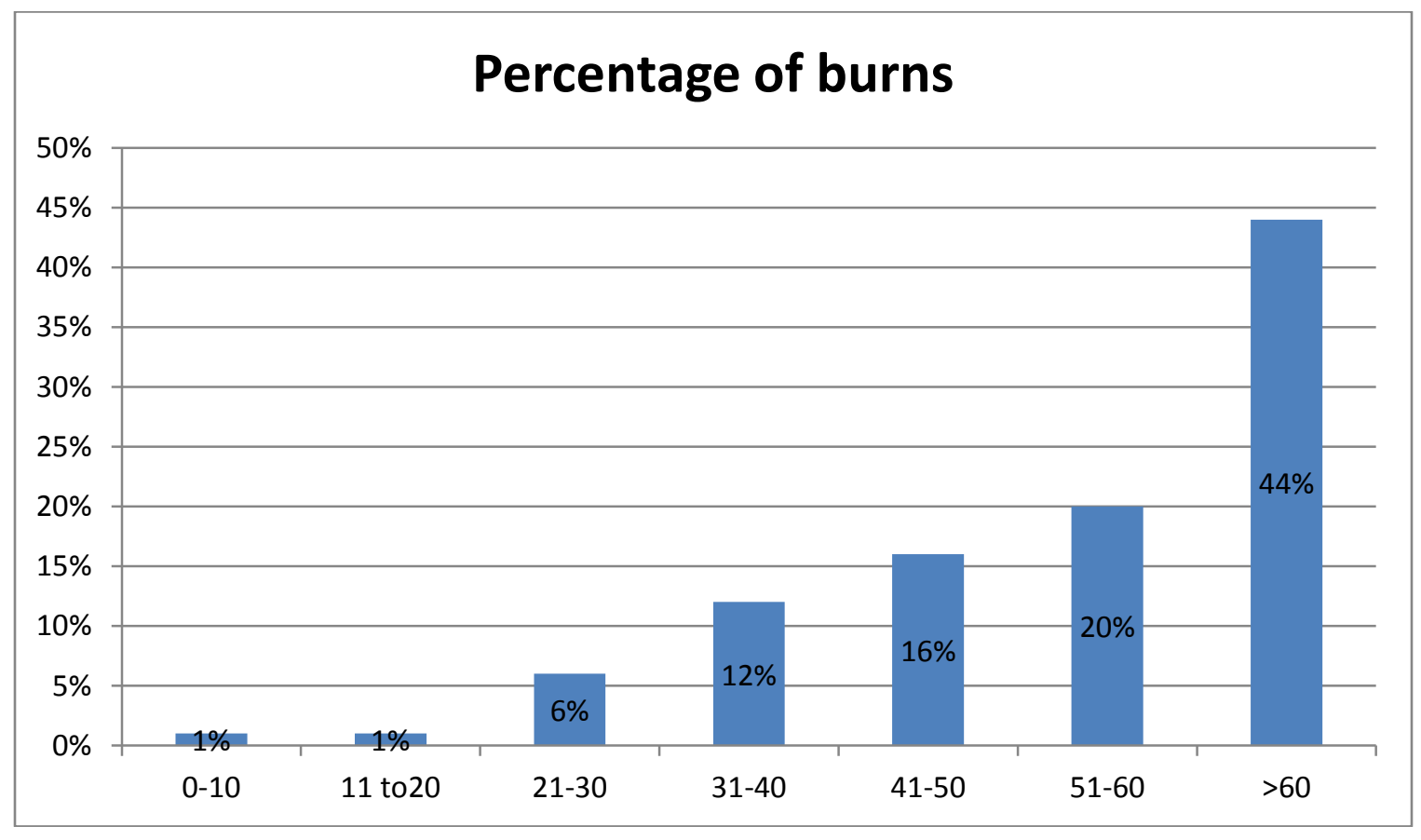

Among 100 patients 44 had $>60 \%$ of burns with involvement of face, 20 patients had 51-60\%burns, 16had 41-50\% burns, 12 had $31-40 \%$ burns, 6 had 20-30\% burns and 10-20\% burns seen in only $1 \%$ of patients. 


\section{Ocular Findings: Acute manifestations}

Eyebrows - $84 \%$ - Loss of eye brows

Eye lids $\quad-85 \%$ - partial and total thickness burns

Conjunctiva - 78\% - Hyperaemia and chemosis.

Sclera - $56 \%$ - Ischaemia, necrosis.

Cornea $\quad-64 \%$ Edema, ulcers.

Uvea $\quad-8 \%$ Iritis

Lens $\quad-12 \%$ Cataract.

Fundus findings-3\% - Retinaledema, Macular edema.

Lacrimal apparatus- 82\% - Epiphora, Dry eye, punctual stenosis.

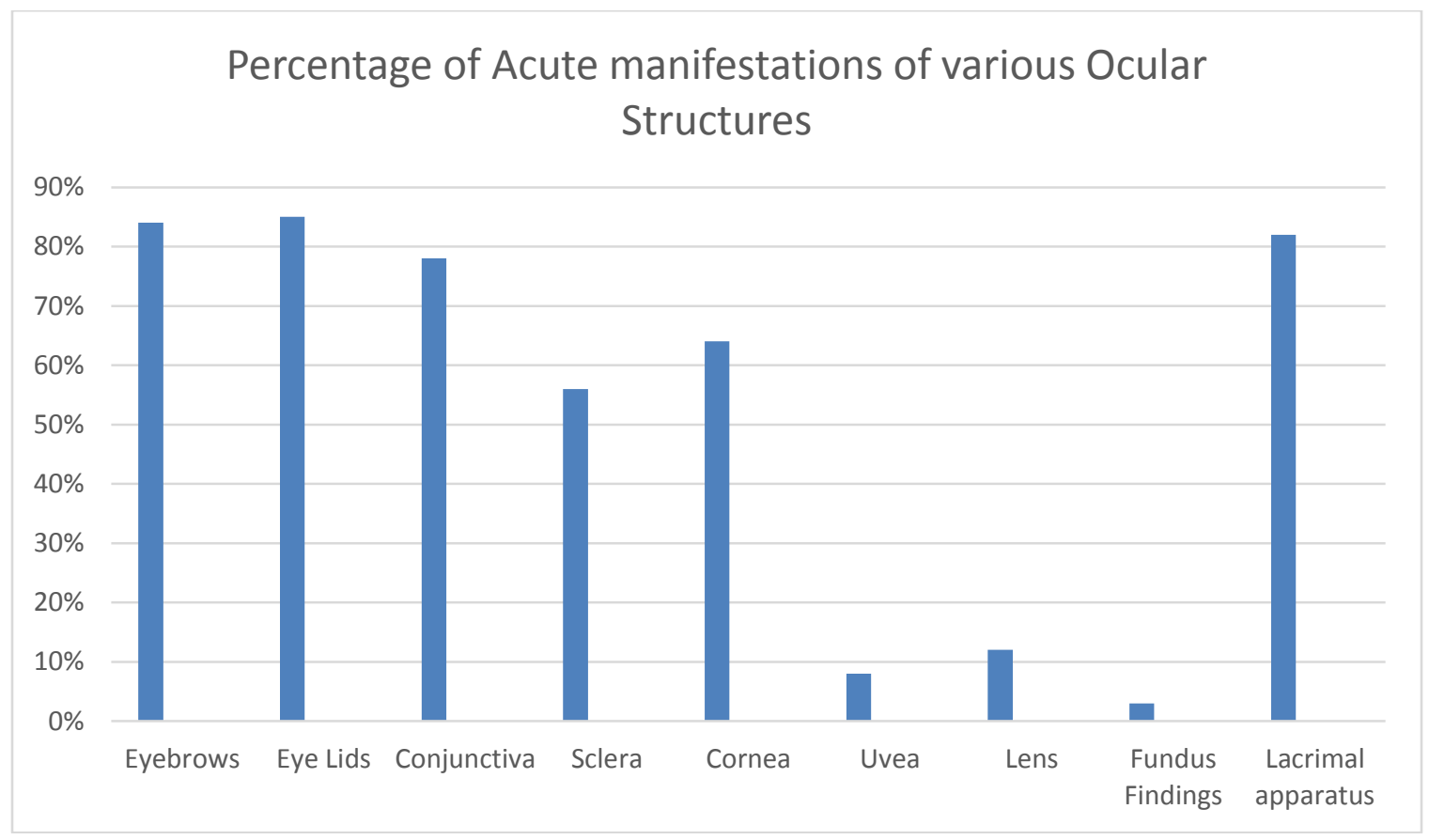

Patients with $>50 \%$ of burns had death among 100 patients, and only 25 patients came for follow up, and detailed ocular examination was conducted, the following findings were made.

Deformities: Chronic (sequelae)

Eye brow - $82 \%$ - Loss of eye brows

Eye lids $\quad-85 \%$ - Ectropion, canthal webbing, Trichiasis, Distichiasis, Lagophthalmos.

Conjunctiva - $82 \%$ Xerosis, Symblepharon.

Cornea $\quad-70 \%$ - Xerosis, Corneal opacity.

Lens $-2 \%$ - Cataract.

Fundus $\quad-3 \%$ - Macular hole.

Lacrimal apparatus - 82\%- Misdirected punctum, Stenosis, Scarring.

\section{Conclusion:-}

Current study showed that 21-30 yrs age group commonly involved in ocular burns, females are commonly affected $(76 \%)$, thermal burns $(84 \%)$ are common, $44 \%$ of patients had $>60 \%$ of burns and eyelids are commonly involved (85\%) followed by eye brows (84\%), Lacrimal apparatus and conjunctiva (78\%). Common sequelae are ectropion (85\%), dry eyes (80\%) and corneal opacity (70\%) leading to corneal blindness.

\section{References:-}

1. Achauer BM, Adair SR. Acute and reconstructive manage- ment of the burned eyelid. Clin Plast Surg. 2000;7:87-95 
2. Barrow RE, Marc KM, David H. Early release of third-degree burns prevents eye injury. Plast Reconstr Surg. 2000;105(3): 860-3

3. Bouchard CS, Morno K, Jeffrey P, et al. Ocular complications of thermal injury: a 3-year retrospective. J Trauma. 2001; 50(1):79-82

4. Cole JK, Engrav LH, Heimbach DM, et al: Early excision and grafting of face and neck burns in patients over 20 years. Plast Reconstr Surg 2002; 109: 1266-1273

5. Raman M., Ijaz S, and Baljit D. The management of Eyelid Burns. Survey of ophthalmology. Volume 54. June 2009

6. Orbit, eyelids, and lacrimal system. (2012). San Francisco, CA: American Academy of Ophthalmology.

7. Hong, J., Qiu, T., Wei, A. et al. Clinical characteristics and visual outcome of severe ocular chemical injuries in Shanghai. Ophthalmology. 2010; 117: 2268-2272

8. Saini, J.S. and Sharma, A. Ocular chemical burns-clinical and demographic profile. Burns. 1993; 19: 67-69. 